LBNL-40623

\title{
THE ELIMINATION OF OXIDES OF NITROGEN FROM THE EXHAUST OF A DIESEL ENGINE USING CRYOGENIC AIR SEPARATION
}

\author{
A. Manikowskia , G. Noland ${ }^{\mathrm{a}}$ and M. A. Green ${ }^{\mathrm{b}}$ \\ a Procyon Power Systems Inc. \\ Alameda, CA 94501 \\ b E. O. Lawrence Berkeley National Laboratory \\ University of California \\ Berkeley, CA 94720
}

\begin{abstract}
The high temperatures associated with combustion in diesel Engines produce oxides of nitrogen as a pollutant. Under the Clean Air Act, it is desirable to eliminate both the oxides of nitrogen and particulate matter from diesel engine exhaust gasses. This paper presents a method for eliminating oxides of nitrogen from the exhaust stream by eliminating the nitrogen from the incoming air entering the engine. The proposed cycle for a cryogenic separation system that separates the oxygen and heavy inert gasses from nitrogen in the air is discussed. Much of the power needed to operate the cryogenic separation plant would come from the heated exhaust gas stream from the engine. Since there is almost no nitrogen in the incoming oxidizer stream, the engine can be run much leaner to reduce carbon monoxide, hydrocarbons, and particulate emissions from the engine exhaust stream.
\end{abstract}

\section{INTRODUCTION}

Recent changes in the Clean Air Act call for drastic reductions in ozone and particulate matter from the exhaust streams of internal combustion engines. The ozone in smog is formed by a reaction between unburned hydrocarbons and the oxides of nitrogen in the presence of sunlight. Gasoline and diesel engines produce both unburned hydrocarbons and oxides of nitrogen as by-products of combustion. The diesel engines used widely for trucks and other forms of transportation also produce particulate matter, primarily in the form of unburned carbon. Recent rulings from the Environmental Protection Agency (EPA) call for large reductions in the production of oxides of nitrogen $\left(\mathrm{NO}_{\mathrm{x}}\right.$ nitric oxides) and particulate matter (soot), particularly from automotive diesel engines.

The usual way of reducing the production of the oxides of nitrogen is to reduce the temperature during combustion under a condition where the engine runs rich (fuel rich oxygen poor). Operating a diesel engine this way produces increased emission of carbon monoxide, unburned hydrocarbons and particulate matter in the form of soot. In addition, the engine runs less efficiently and requires catalytic converters on the exhaust stream. Running a diesel engine at the correct fuel to air ratio or slightly lean greatly increases nitrogen oxide production and thus ozone. This is a catch-22 because standard diesel engine air pollution control methods can no longer meet the new air quality standards and more fuel is used by the engine due to inefficient engine operation.

One way to get rid of the oxides of nitrogen is to get rid of the nitrogen in the incoming air stream. Air is 78 percent nitrogen, 21 percent oxygen, 1 percent argon and a number of other gasses (in order of abundance) that include: water, carbon dioxide, neon, helium, 
methane and other hydrocarbons, krypton, hydrogen, nitrous oxide $\left(\mathrm{N}_{2} \mathrm{O}\right)$ and xenon. The nitrogen in the incoming air to a diesel engine could be replaced by recycled carbon dioxide and water from the diesel engine exhaust stream. The primary change in the incoming oxidizer stream to the engine would be a slight increase in the average molecular weight (from 29 to 31 ) and a reduction in the ratio of specific heats (from 1.4 to about 1.35). By removing the nitrogen from the air, the diesel engine can be operated at the stoichiometric point or slightly lean. Operation slightly lean greatly reduces the formation of carbon monoxide, unburned hydrocarbons and carbon soot. Little or no oxides of nitrogen are formed because there is very little nitrogen in the engine oxidizer stream that can be oxidized. Because combustion in the engine is hotter and the fuel is more completely burned, the thermodynamic efficiency of the engine should go up.

This paper presents a way of removing the nitrogen from the incoming air stream to a diesel engine by separating the nitrogen and light gasses from the oxygen and argon in the air. This separation is through a cryogenic air separator that is attached to and is part of the diesel engine cycle.

\section{THE CRYOGENIC AIR SEPARATION CYCLE}

A number of cycles for the separation of nitrogen and oxygen from the air were investigated $^{1}$. The goal was to minimize the amount of energy drawn from the shaft of the diesel engine. In order to do this, waste heat from the exhaust stream was employed and the energy extracted in the refrigerator expander was used to compress the separated nitrogen stream so that it could be used to generate power at the room temperature end of the cycle. Figure 1 below illustrates a promising cycle for extracting the nitrogen from the incoming air stream to the diesel engine. The cycle shown in Figure 1 gets the compressor power for the incoming air from a combination of the engine shaft and an expander for the nitrogen gas separated from the air. Exhaust gas from the engine is used to heat the nitrogen stream before it is expanded and ejected from the system. Table 1 presents the state point conditions for the cycle shown in Figure 1. The cycle shown in Figure 1 and Table 1 delivers a gross power of $75 \mathrm{~kW}(100 \mathrm{HP})$ and a net power of $69.8 \mathrm{~kW}$ (93 HP).

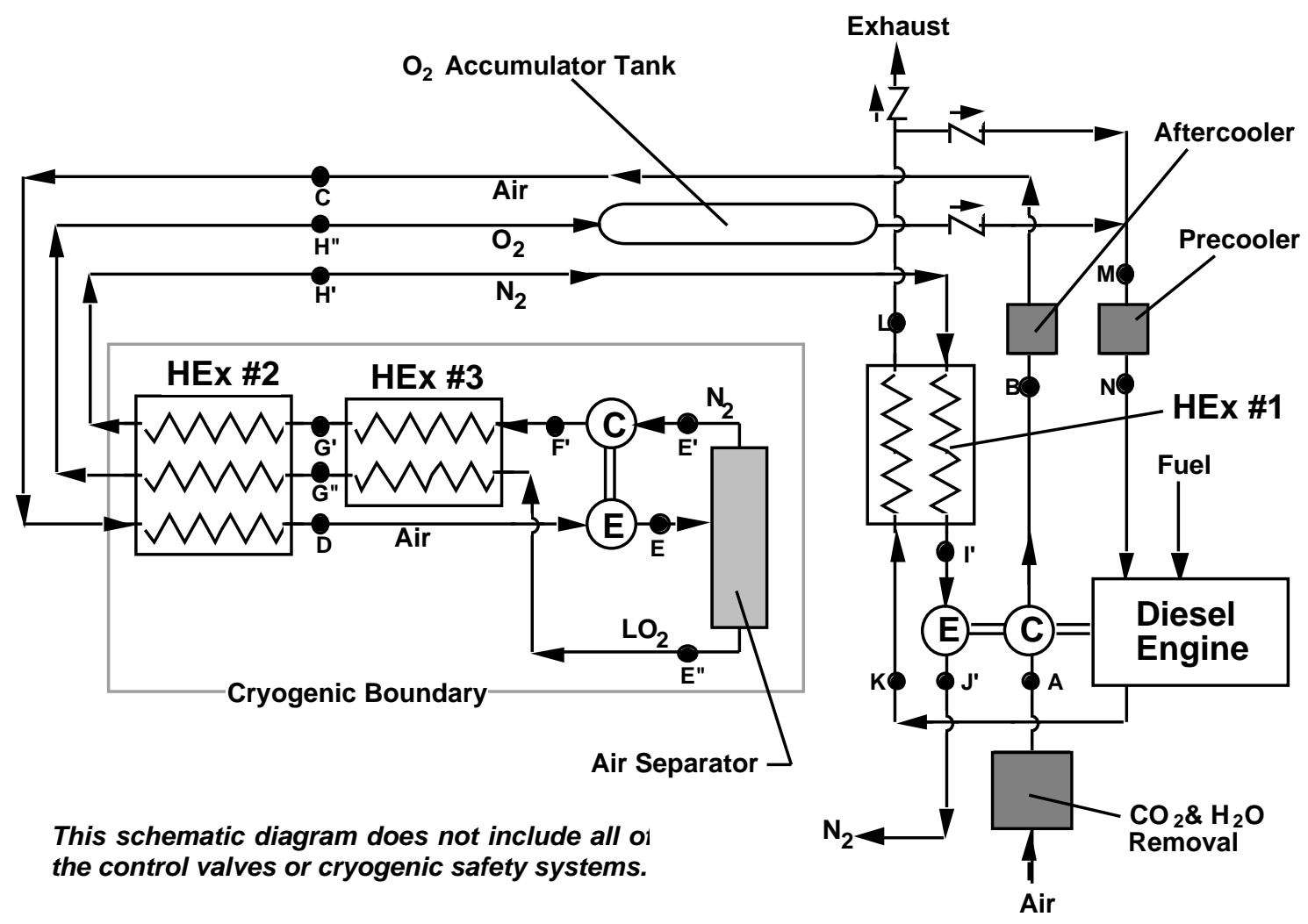

Figure 1 A Schematic Representation of a Cryogenic Air Separation System for Nitrogen Removal from Incoming Air to a Diesel Engine 
Table 1 The State Points for the Diesel Engine Air Separation Cycle shown in Figure 1 (The table includes Constituents, Mass Flow, P, T, H and S.) ${ }^{2}$

\begin{tabular}{|c|c|c|c|c|c|}
\hline State Point & $\begin{array}{c}\text { mass flow } \\
\left(\mathrm{kg} \mathrm{s}^{-1}\right)\end{array}$ & $\begin{array}{c}\mathrm{P} \\
(\mathrm{MPa})\end{array}$ & $\begin{array}{c}\mathrm{T} \\
(\mathrm{K})\end{array}$ & $\begin{array}{c}\mathrm{H} \\
\left(\mathrm{J} \mathrm{g}^{-1}\right)\end{array}$ & $\begin{array}{c}\mathrm{S} \\
\left(\mathrm{J} \mathrm{g}^{-1} \mathrm{~K}^{-1}\right)\end{array}$ \\
\hline $\begin{array}{c}\text { Air Stream } \\
\text { A } \\
\text { B } \\
\text { C } \\
\text { D } \\
\text { E }\end{array}$ & $\begin{array}{l}0.0630 \\
0.0630 \\
0.0630 \\
0.0630 \\
0.0630\end{array}$ & $\begin{array}{l}0.101 \\
2.000 \\
2.000 \\
2.000 \\
0.210\end{array}$ & $\begin{array}{l}300.0 \\
454.1 \\
330.0 \\
\sim 120.0 \\
>85\end{array}$ & $\begin{array}{l}462.4 \\
614.4 \\
486.5 \\
246.1 \\
207.4\end{array}$ & $\begin{array}{l}4.536 \\
4.086 \\
3.754 \\
2.554 \\
2.666\end{array}$ \\
\hline $\begin{array}{c}\text { N2 Stream } \\
E^{\prime} \\
F^{\prime} \\
G^{\prime} \\
H^{\prime} \\
I^{\prime} \\
J^{\prime}\end{array}$ & $\begin{array}{l}0.0484 \\
0.0484 \\
0.0484 \\
0.0484 \\
0.0484 \\
0.0484\end{array}$ & $\begin{array}{l}0.200 \\
0.800 \\
0.800 \\
0.800 \\
0.800 \\
0.101\end{array}$ & $\begin{aligned} & 83.4 \\
& \sim 137 \\
& \sim 104 \\
& \sim 310 \\
& 880.0 \\
& 543.2\end{aligned}$ & $\begin{array}{c}231.1 \\
281.0 \\
\sim 222 \\
470.1 \\
1063.8 \\
716.2\end{array}$ & $\begin{aligned} & 2.840 \\
& \sim 2.890 \\
& \sim 2.58 \\
& 3.821 \\
& 4.952 \\
& 5.023\end{aligned}$ \\
\hline $\begin{array}{c}\mathrm{O}_{2} \text { Stream } \\
\text { E" } \\
\text { G" } \\
\mathrm{H}^{\prime \prime}\end{array}$ & $\begin{array}{l}0.0146 \\
0.0146 \\
0.0146\end{array}$ & $\begin{array}{l}0.200 \\
0.200 \\
0.200\end{array}$ & $\begin{array}{r}97.0 \\
97.0 \\
\sim 310\end{array}$ & $\begin{array}{r}71.6 \\
277.5 \\
475.0\end{array}$ & $\begin{array}{l}0.945 \\
3.090 \\
4.164\end{array}$ \\
\hline $\begin{array}{c}\text { Engine Exh } \\
\text { K } \\
\text { L } \\
\text { M } \\
\text { N }\end{array}$ & $\begin{array}{l}\text { ream } \\
0.0773 \\
0.0773 \\
0.0773 \\
0.0773\end{array}$ & $\begin{array}{l}0.130 \\
0.130 \\
0.130 \\
0.130\end{array}$ & $\begin{aligned} & 900.0 \\
& 543.7 \\
\sim & 504 \\
\sim & 330\end{aligned}$ & $\begin{array}{l}942.3 \\
569.3 \\
\sim 528 \\
\sim 337\end{array}$ & $\begin{array}{l}\mathrm{NC} \\
\mathrm{NC} \\
\mathrm{NC} \\
\mathrm{NC}\end{array}$ \\
\hline $\begin{array}{l}\text { Shaft P } \\
\text { Warm } \\
\text { Cold Ai } \\
\text { Cold N } \\
\text { Warm I } \\
\text { Engine } \\
\text { Net Die } \\
\text { Fuel Bu }\end{array}$ & $\begin{array}{l}\text { tenerated by } \\
\text { npressor, P } \\
\text { ander, Point } \\
\text { Compress } \\
\text { en Expande } \\
\text { Power need } \\
\text { gine Shaft P } \\
\text { e to Genera }\end{array}$ & $\begin{array}{l}\text { sel Engi } \\
B= \\
B=0.8 \\
E^{\prime} \text { to } F \\
I^{\prime} \text { to } J^{\prime} \text {. } \\
\text { the Ail } \\
\text { the Loa } \\
\text { aft Pow }\end{array}$ & $\begin{array}{l}\text { W) } \\
\text { nput Po } \\
\text { tput Pov } \\
0.85 \text {, In } \\
9 \text { Outpu } \\
\text { t }(\mathrm{kW}) \\
\mathrm{V}) \\
\left.\mathrm{g} \mathrm{s}^{-1}\right)\end{array}$ & $\begin{array}{l}\text { V) } \\
\text { ver }(\mathrm{kW}) \\
(\mathrm{kW})\end{array}$ & $\begin{array}{c}75.00 \\
22.02 \\
2.44 \\
2.42 \\
16.82 \\
5.20 \\
69.80 \\
0.0043\end{array}$ \\
\hline
\end{tabular}

With the state point values given in Table 1, about seven percent of the shaft power is used to separate the nitrogen from the incoming air. If there were no recovery of energy within the cycle the power needed to separate the nitrogen from the incoming air would be about 30 percent of the shaft power of the engine. In order to reduce, the incoming shaft power needed to separate the nitrogen from the air one must recover the expansion engine power and use it to recompress the nitrogen. One must also use the heat from the exhaust gasses to help drive the input air compressor. The amount of shaft power saved depends on the efficiency of the compressors, the expanders and the heat exchangers. The state point values given in Table 2 are values that might be achievable if the right types of components are selected.

\section{Efficient Compressors and Expanders}

The warm compressor is assumed to have an efficiency of 90 percent as compared to isentropic compression. The cold compressor is assumed to have an efficiency that is 85 percent of isentropic compression. Isothermal compression requires less power than isentropic compression, so the secret to achieving efficiency that is high compared to isentropic is to stage the compression with intercoolers to approach isothermal compression ${ }^{3}$. 
The single warm compressor shown in Figure 1 can be replaced with a staged compressor with intercoolers between stages and an after cooler after the final stage of compression. A three stage warm compressor is illustrated on the left hand side of Figure 2. Water cooled intercoolers are after stages one and two and a water cooled after cooler is after the third stage. This reduces the compressor input power needed to compress the gas and it reduces the temperature of the gas entering the cold box heat exchangers.

Inter cooling can also be applied to the cold compressor. A two stage cold compressor with intercooling and after cooling is illustrated on the right side of Figure 2. The liquid oxygen stream can be used to provide the intercooling and aftercooling for the compressed nitrogen stream.

Both the warm compressor and the cold compressor should be of the positive displacement type. Scroll compressors or a lubricated piston compressor should be considered. Some development is needed to achieve the level of compressor efficiency quoted in Table 2.

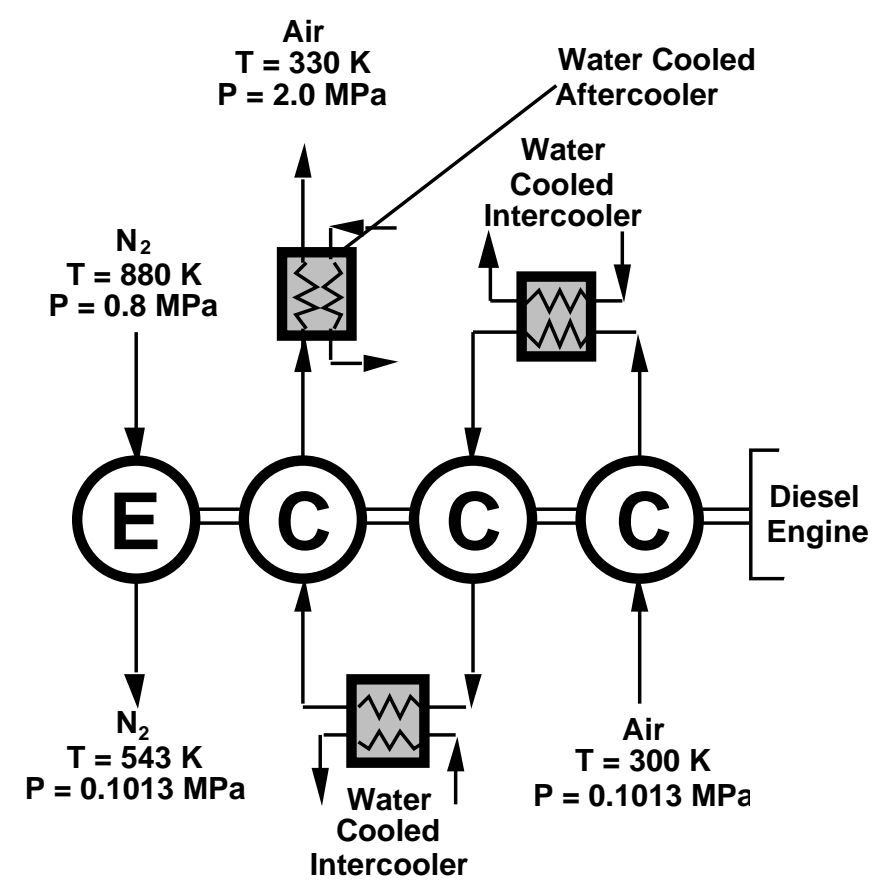

a) Air Compression System

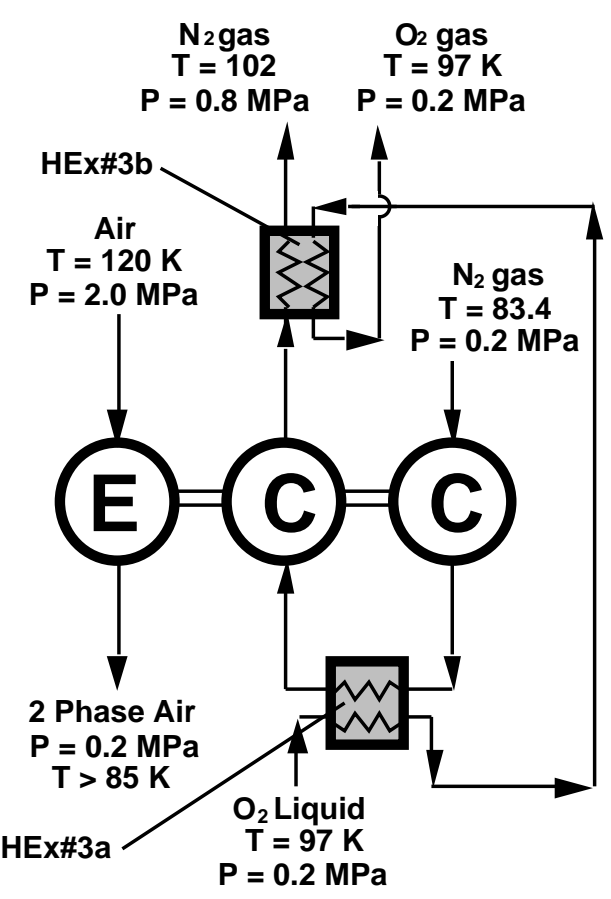

b) Nitrogen Recompression

Figure 2 A Schematic Representation of Warm and Cold Multistage Compressors from the Cycle Shown in Figure 1 with Intercoolers and Aftercoolers

The expander efficiency quoted may be achievable with positive displacement expanders now being used. The expander has to be compatible with the cold compressor that is being proposed. Both machines will share a common shaft and would operate at the same speed. A vane or scroll type of expander capable of operating within the two-phase region is needed. Considerable development work may be needed to achieve an efficient reliable expander that con be coupled to the cold compressor.

\section{Efficient Separation of Nitrogen from Argon and Oxygen}

Efficient separation of the oxygen (plus argon and other heavy gasses) and nitrogen (plus the light gasses) reduces the amount of incoming air that needs to be processed. Efficient separation reduces the amount of nitrogen introduced into the engine and the amount of $\mathrm{NO}_{\mathrm{x}}$ that is produced by the engine. A simple cyclone separator is probably not adequate for efficient air separation. A fractionating column with a reflux condenser and a reboiler will do a nice job of separating the air gases so that the oxygen stream contains less than a few percent nitrogen. Conversely little of the oxygen is lost in the nitrogen stream. 
A packed column separator with plenty of contact surface can be used for gas separation as long a there is an oxygen reboiler at the lower end of the column and there is a nitrogen reflux condenser at the upper end of the column ${ }^{4}$. A schematic for a packed column separator with reboil and reflux is shown in Figure 3.

Heat for the reboiler is supplied by using warm nitrogen from the cold compressor. The nitrogen can be reintroduced back into the nitrogen stream, between compression stages with some loss of compression efficiency. Only a small percentage of the nitrogen stream is used for reboiling the oxygen. Cold for the reflux condenser can be supplied by expanding liquid nitrogen at the $\mathrm{G}^{\prime}$ end of heat exchanger HEx \#3. This liquid nitrogen is expanded to about $0.12 \mathrm{MPa}$ to provide the cooling to the reflux compressor. The nitrogen used to cool the reflux condenser can either be recompressed to the pressure at $E^{\prime}$ (with an oxygen cooled after cooler) or the cold from the reflux condenser cooling stream can be recovered provided an extra pass is added to heat exchanger HEx \#3 and HEx \#2. The flow in the reflux condenser cooling stream is expected to low.

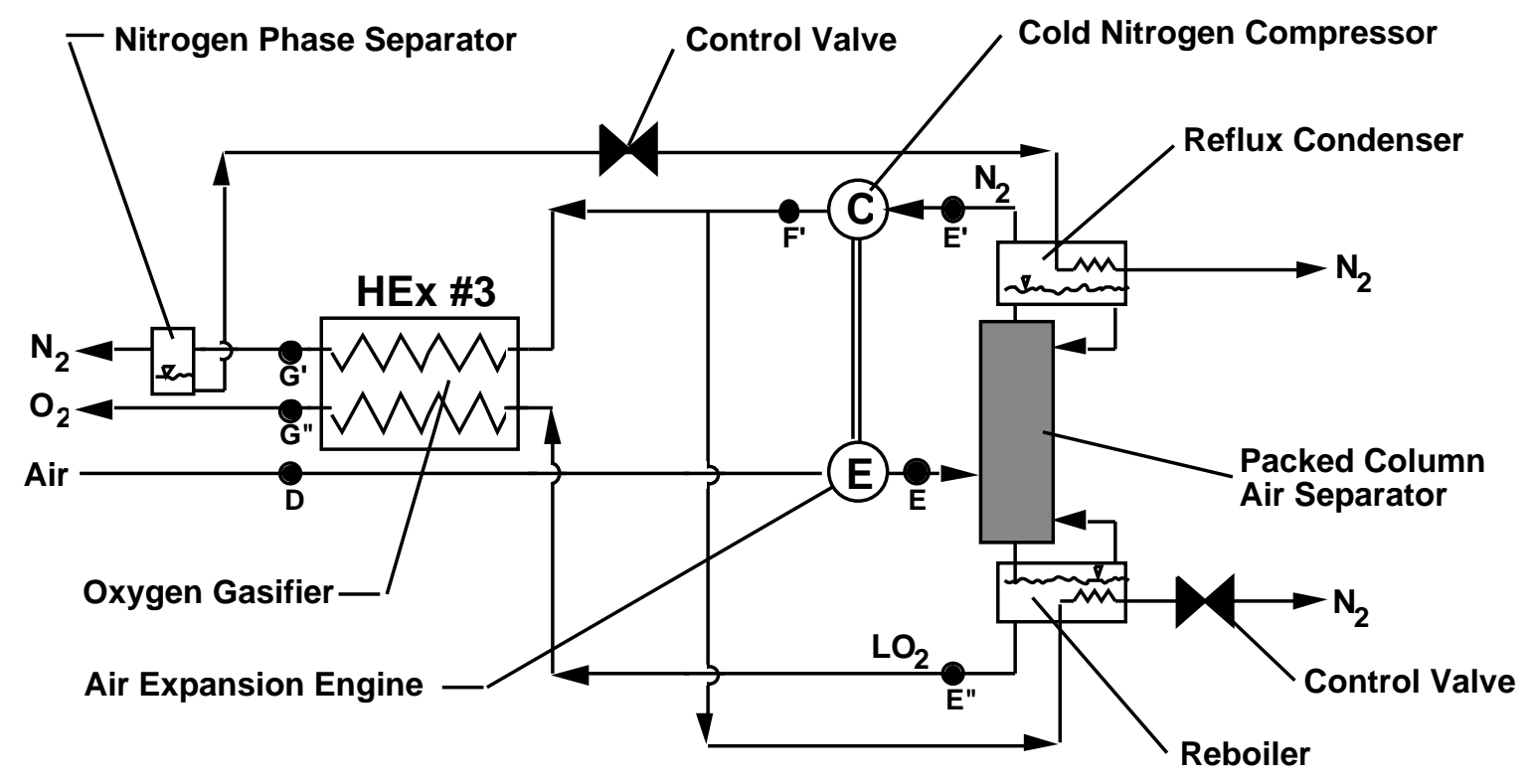

This schematic diagram does not include all of the control valves or cryogenic safety systems.

Figure 3 Reflux and Reboil to Improve Air Separation Efficiency

\section{Heat Exchangers for the Air Separator}

Ordinary tube and shell heat exchangers would be too large and too expensive for a compact air separation plant for a diesel engine. Compact heat laminar flow heat exchangers, that have boundary layer thicknesses from 0.5 to $1.5 \mathrm{~mm}$ appear to be attractive for this application. Table 2 shows the parameters for the laminar flow heat exchangers

Table 2 The Log Mean Î T5, U Factor, and Area for the Heat Exchangers in Figure 1

$\begin{array}{ccccccc}\text { HEx \# } & \begin{array}{c}\mathrm{Q} \\ (\mathrm{kW})\end{array} & \begin{array}{c}\mathrm{T}_{\mathrm{LM}} \\ (\mathrm{K})\end{array} & \begin{array}{c}\mathrm{h}_{\mathrm{c} 1} \\ \left(\mathrm{~W} \mathrm{~m}^{-2} \mathrm{~K}^{-1}\right)\end{array} & \begin{array}{c}\mathrm{h}_{\mathrm{c} 2} \\ \left(\mathrm{~W} \mathrm{~m}^{-2} \mathrm{~K}^{-1}\right)\end{array} & \begin{array}{c}\mathrm{U} \\ \left(\mathrm{W} \mathrm{m}^{-2} \mathrm{~K}^{-1}\right)\end{array} & \begin{array}{c}\text { Area } \\ \left(\mathrm{m}^{2}\right)\end{array} \\ & & & & & & \\ 1 & 2.88 & 87.4 & 97.1^{*} & 20.4^{* *} & 16.8 & 19.6 \\ 2 & 15.25 & 20.1 & 33.4^{*} & 33.4^{*} & 16.7 & 45.4 \\ 3 & 3.01 & 12.9 & \sim 21.0^{*} & \sim 360 & 19.8 & 11.8\end{array}$

* The boundary layer thickness in the laminar heat exchanger is about $0.5 \mathrm{~mm}$.

** Due to fouling, the flow passage must be larger, the boundary layer thickness is $1.5 \mathrm{~mm}$. 
The laminar flow heat exchangers can be made from etched copper plates that have cooling passages that are $1 \mathrm{~mm}$ deep. The heat exchanger between the engine exhaust stream and the nitrogen gas returning from the cold box may have to be made from another material. The passages on the exhaust side of this heat exchanger would be about $3 \mathrm{~mm}$ deep. On the nitrogen side (not subject to fouling), the passage depth would be only about $1 \mathrm{~mm}$. Depending on how the flow passages are shaped, extended heat transfer surfaces can be created. The laminar flow heat exchangers would have many passages in parallel so the pressure drop along the heat exchanger would be quite low. The estimated physical size for the three heat exchangers shown in Figure 1 are: HEx \#1 would be $1.0 \mathrm{~m}$ long, $0.4 \mathrm{~m}$ wide, and $0.4 \mathrm{~m}$ thick. HEx \#2 would be $1.0 \mathrm{~m}$ long, $0.5 \mathrm{~mm}$, and $0.5 \mathrm{~m}$ thick. HEx \#3 would be $0.2 \mathrm{~m}$ long, $0.5 \mathrm{~m}$ wide, and $0.5 \mathrm{~m}$ thick. Heat exchanger HEx \#3 can be subdivided to provide the intercooling needed for the cold compressor. The whole cold box assembly including the expander, the cold compressor, and the air separation column could fit in a vacuum cylinder with dished heads that is 0.85 meters in diameter by 1.7 meters long.

\section{Heat Exchanger Fouling, Air Purification and Other Issues}

Heat exchanger fouling is an issue on the exhaust side of HEx\#1 where unburned carbon and hydrocarbons can be deposited in the heat exchanger passages. Fouling in this heat exchanger will be minimized if the particulate matter and unburned hydrocarbons are burned as fuel in an oxygen rich atmosphere.

Fouling may also be a problem on the air side HEx\#2. The problem here is water vapor, carbon dioxide, hydrocarbons (ethane and above) krypton and xenon. Air at $305 \mathrm{~K}$ (32 C) can contain up to 29 grams of water for each kilogram of air ${ }^{3}$. The cycle shown in Table 1 processes about $227 \mathrm{~kg}$ of air per hour. This means that $6600 \mathrm{~g}$ of water, $113.5 \mathrm{~g}$ of carbon dioxide, $0.75 \mathrm{~g}$ of krypton, about $0.2 \mathrm{~g}$ of higher hydrocarbons and $0.09 \mathrm{~g}$ of xenon are also involved the process 6 . Krypton, higher hydrocarbons and xenon can be taken care of by molecular sieve purifiers that are in the middle of HEx \#2. Methane will also be removed by these purifiers, but it does not have to be. Whether or not these purifiers have to be recharged depends on the number of hours the engine runs without being shut off.

The real problem is the water and carbon dioxide that enter the cycle with the air. Molecular sieve or silica gel desiccants can remove both water and carbon dioxide. How much carbon dioxide is removed depends on the temperature of the desiccant. Purifiers needed to remove the water can be at the entrance to the air compressor (see Figure 1), but to remove carbon dioxide a purifier may have to be somewhere in the upper end of heat exchanger HEx \#2. Purifiers for removing water and carbon dioxide must be recharged periodically. The nitrogen coming from the expander at a temperature of $543 \mathrm{~K}(270 \mathrm{C})$ can be used to recharge both the water and carbon dioxide purifiers.

The cycle shown in Figure 1 and Table 1 shows a temperature after precooler on the mixed gas stream entering the engine (point $\mathrm{N}$ ) of $350 \mathrm{~K}$. It is desirable to have the gas entering the engine at as low a temperature as possible, but lowering this temperature below $345 \mathrm{~K}$ will result in the condensation of water in this stream. The mass flow of the oxidizer stream into the engine is reduced 14 percent compared to an air stream at $300 \mathrm{~K}$. One can compensate for the reduced mass flow by increasing the percentage of oxygen in the oxidizer stream to about 25 percent by volume. The oxidizer stream ( 25 percent oxygen) that enters the engine will have a ratio of specific heats of 1.354 and a molecular weight of 30.4. Normal air (21 percent oxygen) has a ratio of specific heats of 1.4 and a molecular weight of 29. How one controls the amount of oxygen in the oxidizer stream may be an issue.

\section{CONCLUDING COMMENTS}

It is desirable to remove oxides of nitrogen, particulate matter (carbon), carbon monoxide and unburned hydrogen from the exhaust stream of internal combustion engines. One can greatly reduce particulate matter, carbon monoxide and unburned hydrocarbons by burning fuel in the engine with a slight amount of excess oxygen. This greatly increases the amount of $\mathrm{NO}_{\mathrm{x}}$ produced by the engine.

Removal of nitrogen oxides from the exhaust of a diesel engine can be accomplished by separating the nitrogen and oxygen from the incoming air stream to the engine. The nitrogen is replaced by a mixture of carbon dioxide and water vapor. The engine can now run lean to 
get rid of particulate matter, $\mathrm{CO}$ and unburned hydrocarbons. The use of a cryogenic separation plant to separate nitrogen from the air appears to be feasible technically.

In order to reduce the shaft power needed to separate the incoming air one needs to recover waste heat from the exhaust and one needs to recompress the nitrogen separated at the low temperature lend of the cycle. The power for this recompression would be supplied by a cold expander used to produce liquid air at the low temperature end of the cycle. The amount of shaft power from needed to separate nitrogen depends strongly on the efficiency of the compressors, expanders and the heat exchangers. Multiple stage compression with intercooling and aftercooling is clearly desirable. The colder the gas is between stages, the more efficient the compression will be become compared to an isentropic compressor.

A cycle that has 100 percent efficient compressors and expanders will require no shaft power from the engine to separate the incoming air. (All of the power needed comes from waste heat in the exhaust stream.) For the cycle presented here with less than one hundred percent efficient expanders and compressors, the shaft power used to separate the incoming air represents about seven percent of the shaft power developed by the engine. The increase in efficiency due to higher combustion temperature may, in part, make up for the losses due to air separation inefficiencies.

\section{ACKNOWLEDGMENT}

Over half of this work was done with funds from the private sector. The remainder of the work was performed with the support of the Director, Office of Energy Research, Office of High Energy and Nuclear Physics, High Energy Physics Division, U. S. Department of Energy under Contract No. DE-AC03-76SF00098.

\section{REFERENCES}

1. R. B. Scott, Cryogenic Engineering, D. Van Nostrand Company Incorporated, New York, (1969)

2. V. J. Johnson editor, " Properties of Materials at Low Temperature (Phase 1), a Compendium," Part 1 Properties of Fluids, Pergamon Press, New York (1961)

3. J. B. Jones, and G. A. Hawkins, Engineering Thermodynamics, John Wiley and Sons Incorporated, New York (1960)

4. R. E. Traybal, Mass-Transfer Operations, McGraw-Hill Book Company Incorporated, New York, (1955)

5. F. Kreith, Principles of Heat Transfer, International Textbook Company, Scranton PA, (1961)

6. Handbook of Chemistry and Physics, 58th Edition, p F210, CRC Press, (1977) 
THE ELIMINATION OF OXIDES OF NITROGEN FROM THE EXHAUST OF A DIESEL ENGINE USING CRYOGENIC AIR SEPARATION,

\section{A. Manikowski, G. Noland,}

Procyon Power Systems Inc.

Alameda, CA 94501

\section{A. Green,}

E. O. Lawrence Berkeley National Laboratory

University of California

Berkeley, CA 94720

\section{Cryogenics Engineering Conference \\ Portland, Oregon \\ July 28 through August 1, 1997}

To be published in Advances in Cryogenic Engineering, Vol. 43 (1997)

\footnotetext{
*This work was performed at the Lawrence Berkeley Laboratory with the support of the Director, Office of Energy Research, Office of High Energy and Nuclear Physics, High Energy Physics Division, U. S. Department of Energy under Contract No. DE-AC03-76SF00098.
} 